\title{
Metastatic Breast Lobular Carcinoma Involving Tamoxifen-Associated Endometrial Polyps: Report of Two Cases and Review of Tamoxifen-Associated Polypoid Uterine Lesions
}

\author{
J. P. Houghton, M.B., O. B. Ioffe, M.D., S. G. Silverberg, M.D., B. McGrady, MRCPath, \\ W. G. McCluggage, FRCPath \\ Department of Pathology, Royal Group of Hospitals Trust (JPH, WGMcC), Belfast, Northern Ireland; \\ Department of Pathology, University of Maryland School of Medicine and Medical Center (OBI, SGS), \\ Baltimore, Maryland; and Department of Pathology, Craigavon Area Hospital Trust (BMcG), Craigavon, \\ Northern Ireland
}

\begin{abstract}
Two cases of lobular breast carcinoma metastatic to an endometrial polyp are described. Both patients had been treated with tamoxifen and presented with abnormal uterine bleeding. Histology of endometrial biopsy in both cases showed typical tamoxifen-associated endometrial polyps with focal subtle stromal infiltration by metastatic lobular breast carcinoma. This was confirmed by positive immunohistochemical staining with cytokeratin epithelial markers. Metastatic breast carcinoma may rarely involve tamoxifen-associated endometrial polyps. Because primary endometrial carcinomas may also arise within tamoxifen polyps, these should be extensively sampled. We briefly review polypoid uterine lesions that may occur secondary to tamoxifen therapy.
\end{abstract}

KEY WORDS: Endometrium, Metastatic breast carcinoma, Polyp, Tamoxifen.

Mod Pathol 2003;16(4):395-398

Tamoxifen is a nonsteroidal triphenylethyl compound that is widely used as adjuvant therapy in the treatment of breast cancer. Tamoxifen prolongs overall and disease-free survival, reduces the likelihood of disease in the contralateral breast, and may also reduce the risk of development of breast cancer in asymptomatic women with a strong family history (1, 2). The efficacy of tamoxifen in breast cancer is due to its anti-estrogenic properties (3). However, tamoxifen

Copyright $(\odot) 2003$ by The United States and Canadian Academy of Pathology, Inc.

VOL. 16, NO. 4, P. 395, 2003 Printed in the U.S.A

Date of acceptance: January 28, 2003.

Address reprint requests to: W. G. McCluggage, Department of Pathology, Royal Group of Hospitals Trust, Grosvenor Road, Belfast BT12 6BL, Northern Ireland; fax: 028-90-233643; e-mail: glenn.mccluggage@bll.n-i.nhs.uk.

DOI: 10.1097/01.MP.0000062655.62606.86 may also exert a weak estrogenic effect, resulting in a variety of lesions within the female genital tract. Tamoxifen treatment may result in endometrial proliferative lesions, including simple, complex, and atypical hyperplasia; polyps (single or multiple); polyp cancers; and adenocarcinomas (4-6). Tamoxifen may also result in estrogenic effects on the female genital tract outside the endometrium. For example, squamous epithelial cells of the cervix and vagina may exhibit estrogenic effects postmenopausally $(7,8)$. An increased incidence of adenomyosis and unusual morphological features of adenomyosis has also been described $(9,10)$, as well as proliferative activity and the development of adenocarcinoma in endometriosis (11-13).

Here we describe two cases of metastatic breast lobular carcinoma involving tamoxifen-associated endometrial polyps. We also review polypoid uterine lesions arising in association with tamoxifen.

\section{CASE REPORT}

\section{Case 1}

A 62-year-old woman presented with postmenopausal bleeding and underwent hysteroscopy and removal of an endometrial polyp. She had been taking tamoxifen for 14 months since undergoing mastectomy for an invasive breast lobular carcinoma. The breast carcinoma was $4.5 \mathrm{~cm}$ in maximum dimension. A single axillary lymph node was involved by metastatic carcinoma.

\section{Case 2}

A 92-year-old woman presented with postmenopausal bleeding and underwent an endometrial curettage. She had been taking tamoxifen for 5 years 
since undergoing mastectomy for an invasive lobular carcinoma of breast. The breast carcinoma was $7 \mathrm{~cm}$ in maximum dimension. Lymph node dissection was not performed at the time of mastectomy.

\section{PATHOLOGICAL FINDINGS}

The specimen in Case 1 consisted of a $3-\mathrm{cm}-$ diameter polyp, and the specimen in Case 2 consisted of a 3-cm-diameter polyp, together with separate fragments of endometrium.

Histology of both cases showed an endometrial polyp containing glandular structures, many of which were cystically dilated, set in a fibrovascular stroma. In areas there was slight condensation of stroma around the glands. Focally the glands showed ciliated metaplasia in Case 1 and mucinous metaplasia in Case 2. In one focus in Case 1, involving a small area of the polyp, the stroma was more cellular, and high-power examination showed a monotonous population of epithelial cells with a moderate amount of clear cytoplasm (Fig. 1). Similarly, in Case 2, involving about 25\% of the polyp, the stroma was hypercellular, and again, highpower examination showed a monotonous population of epithelial cells with a moderate amount of eosinophilic cytoplasm (Fig. 2). In both cases, intracytoplasmic lumina and signet ring cells were present. Histology of the separate small fragments of endometrium in Case 2 showed weakly proliferative endometrium with no tumor infiltration.

Immunohistochemical staining of both cases with AE1/3 (DAKO, Ely, United Kingdom) showed strong positivity of the glandular elements of the polyp and of the foci of epithelial cells within the stroma (Figs. $3-4)$. The rest of the stroma was negative.

The features in both cases were in keeping with focal involvement of the stroma of the polyp by metastatic breast lobular carcinoma.

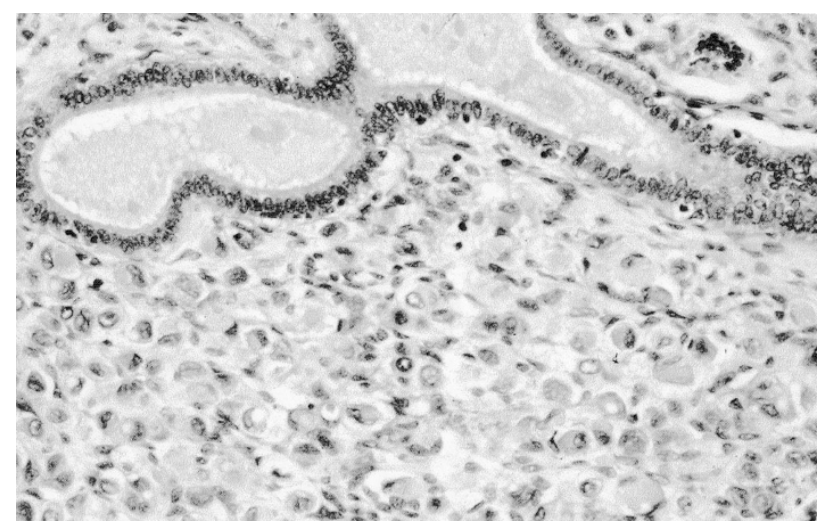

FIGURE 1. Monotonous population of epithelial tumor cells within stroma of polyp in Case 1.

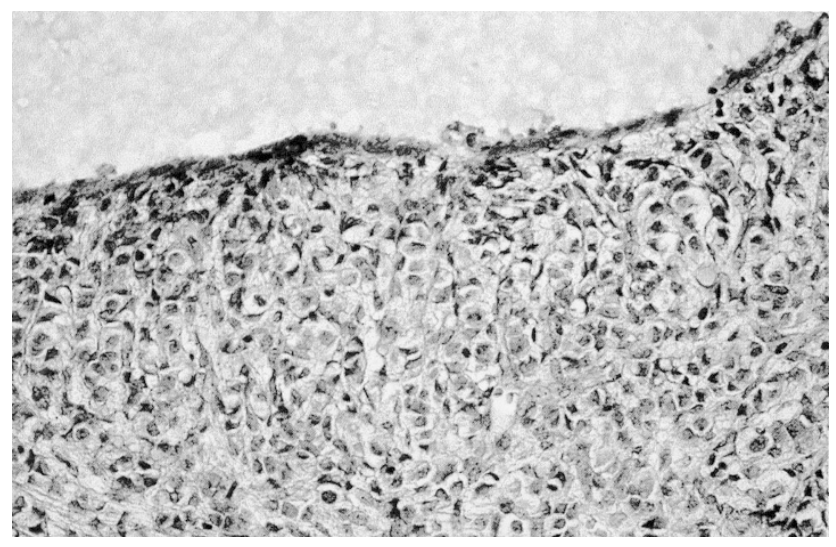

FIGURE 2. Monotonous population of epithelial tumor cells within stroma of polyp in Case 2.

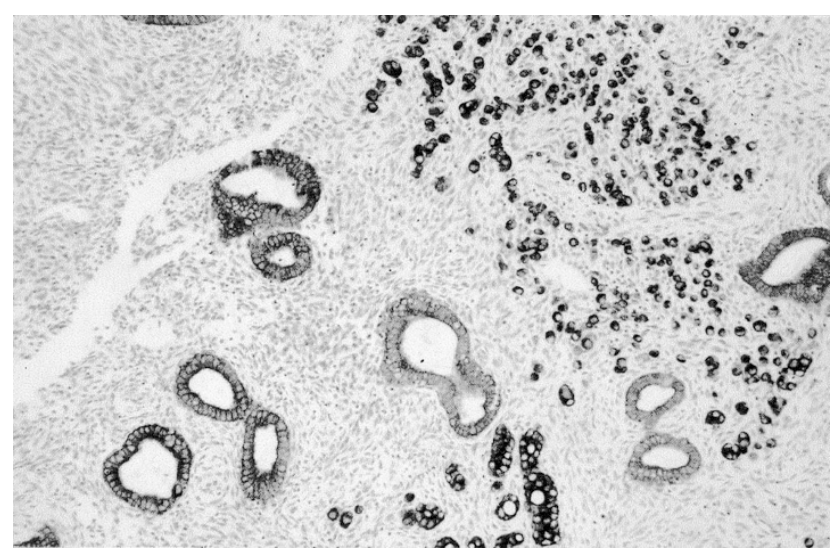

FIGURE 3. AE1/3 stain showing positivity of the glandular epithelium and epithelial tumor cells in Case 1.

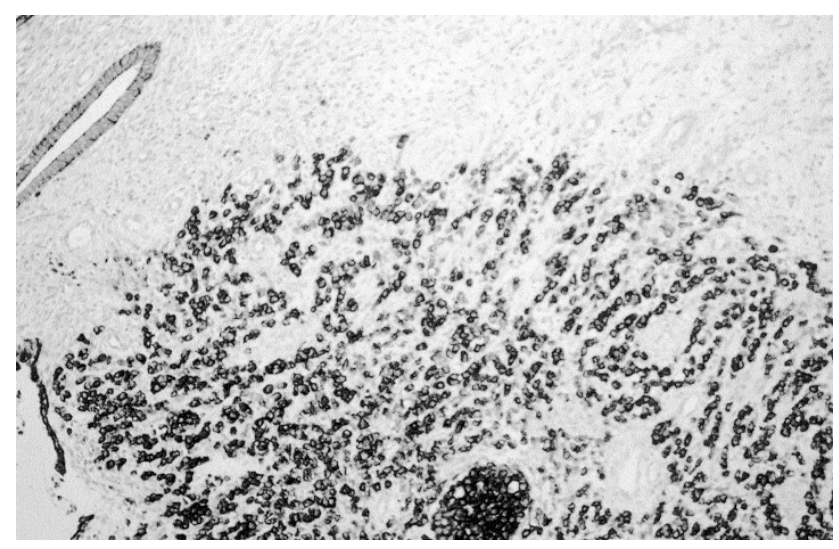

FIGURE 4. AE1/3 stain showing positivity of the glandular epithelium and epithelial tumor cells in Case 2.

\section{DISCUSSION}

Metastases to the endometrium from outside the female genital tract are rare. Most commonly the primary tumor is in the breast, gastrointestinal tract, lung, pancreas, kidney, or skin (malignant melanoma; 14, 15). The myometrium is a much more common site of metastasis from extragenital 
neoplasms. Kumar and Hart (14) found only two cases of endometrial secondaries among 63 metastatic uterine neoplasms, whereas Mazur et al. (15) identified seven secondaries within the endometrium in 149 cases of extragenital neoplasms metastatic to the female genital tract.

Endometrial polyps, which may be multiple, are characteristic complications of tamoxifen therapy (4-6). The two polyps we describe were characterized by glandular metaplastic changes and periglandular stromal condensation. These features are characteristic, but not pathognomonic, of tamoxifen-associated endometrial polyps. In both cases, the stroma of the polyp was focally infiltrated by metastatic breast lobular carcinoma. This was easily missed at scanning magnification because the tumor cells resembled plump endometrial stromal cells. Diagnosis was made on high-power examination and was confirmed by positive immunohistochemical staining with the anti-cytokeratin epithelial marker $\mathrm{AE} 1 / 3$, the endometrial stromal cells being negative.

As far as we are aware, there have been only three previously reported cases of metastatic breast carcinoma involving an endometrial polyp, one each of lobular, ductal, and apocrine type (16-18). The two cases we report suggest that lobular carcinoma has a particular propensity to involve endometrial polyps, in keeping with the observation that this type of breast carcinoma is most likely to metastasize to the female genital tract. In one of the previously reported cases, the endometrial polyp appears to have been tamoxifen associated (17). It was not stated in the other two reports whether the patients were taking tamoxifen.

The cases reported herein suggest that tamoxifenassociated endometrial polyps should be extensively sampled to ensure that small foci of metastatic breast carcinoma are not missed. Additionally, especially in tamoxifen-associated endometrial polyps, but occasionally in sporadic polyps, primary endometrial carcinomas may arise, so-called polyp cancers (4). These are usually of endometrioid type and may be confined to the polyp (4).

Uterine serous carcinoma (USC), the prototype of Type II endometrial cancer, has a propensity to arise in or to involve and largely be confined to otherwise benign endometrial polyps (19-21). It might be expected that USC, and its precursor lesion endometrial intraepithelial carcinoma (EIC), could also arise in tamoxifen-associated endometrial polyps, and indeed, one of us (WGM) has noted this phenomenon elsewhere in a small number of cases (22). This is additional evidence of the need to extensively sample tamoxifen-associated endometrial polyps. It has, in fact, been suggested that endometrial carcinomas associated with tamoxifen therapy are more likely to be high-grade neoplasms, such as USC, rather than low-grade endometrioid carcinomas (23).

Other polypoid uterine lesions that may occur in association with tamoxifen include the group of mixed Müllerian tumors. Adenofibromas, adenosarcomas, and carcinosarcomas (malignant mixed Müllerian tumors) have all been described with tamoxifen (24-28). Although it seems likely that there is an association between uterine carcinosarcoma and tamoxifen therapy (especially long-term), it is not clear whether there is an association with adenofibroma and adenosarcoma because only a few cases have been reported. It is possible that the tamoxifen association in these cases is coincidental. It has been suggested that the periglandular stromal condensation often found in tamoxifen polyps may, in some cases, represent transformation to adenosarcoma (27).

Endometrial stromal sarcomas (29) and uterine leiomyosarcomas $(23,30)$ have also been reported in association with tamoxifen, as has rapid growth of uterine leiomyomas $(31,32)$. These neoplasms may present as polypoid lesions projecting into the endometrial cavity. Again it is unclear whether a true association exists between tamoxifen therapy and the development of these lesions or whether their occurrence is coincidental.

In summary, we report two cases of metastatic breast lobular carcinoma involving tamoxifenassociated endometrial polyps. Pathologists should be aware of the possibility of focal involvement of tamoxifen polyps by metastatic breast carcinoma and should examine such polyps carefully and extensively. As a rule, we would recommend that at least one section per centimeter of maximum polyp dimension should be examined.

\section{REFERENCES}

1. Early Breast Cancer Trialists' Collaborative Group. Systematic treatment of early breast cancer by hormonal, cytotoxic or immune therapy. 133 randomised trials involving 31000 recurrences and 24000 deaths among 75000 women. Lancet 1992;339:1-15.

2. Early Breast Cancer Trialists' Collaborative Group. Tamoxifen for early breast cancer: an overview of the randomised trials. Lancet 1998;351:1451-67.

3. Wakeling AE, Bowler J. Biology and mode of action of pure antiestrogens. J Steroid Biochem 1988;30:141-7.

4. Ismail SM. Pathology of endometrium treated with tamoxifen. J Clin Pathol 1994;47:827-33.

5. Neven P, De Muylder X, Van Belle Y, Venderick G, De Muylder E. Tamoxifen and the uterus and endometrium. Lancet 1989;1:375.

6. Schlesinger C, Kamoi S, Ascher SM, Kendall M, Lage JM, Silverberg SG. Endometrial polyps: a comparison study of patients receiving tamoxifen with two control groups. Int J Gynecol Pathol 1998;17:302-11.

7. Ferrazzi E, Cartei G, Mattarazzo R, et al. Oestrogen-like effect of tamoxifen on vaginal epithelium. BMJ 1997;1:1351-2. 
8. Eells TP, Alpern HD, Gzywacz C, et al. The effect of tamoxifen on cervical squamous maturation in Papanicolaou stained cervical smears of postmenopausal women. Cytopathology 1990;1:263-8.

9. Cohen I, Beyth Y, Shapira J. High prevalence of adenomyosis in postmenopausal breast cancer patients treated with tamoxifen. Gynecol Obstet Invest 1997;44:200-5.

10. McCluggage WG, Desai V, Manek S. Tamoxifen-associated postmenopausal adenomyosis exhibits stromal fibrosis, glandular dilatation and epithelial metaplasias. Histopathology 2000;37:340-6.

11. McCluggage WG, Bryson C, Lamki H, Boyle DD. Benign, borderline and malignant endometrioid neoplasia arising in endometriosis in association with tamoxifen therapy. Int J Gynecol Pathol 2000;19:276-9.

12. Cohen I, Altaras MM, Lew S, et al. Ovarian endometrioid carcinoma and endometriosis developing in a postmenopausal breast cancer patient during tamoxifen therapy: a case report and review of the literature. Gynecol Oncol 1994; 55:443-7.

13. Schlesinger C, Silverberg SG. Tamoxifen-associated polyps (basalomas) arising in multiple endometriotic foci: a case report and review of the literature. Gynecol Oncol 1999;73: 305-11.

14. Kumar NB, Hart WR. Metastases to the uterine corpus from extragenital cancers. A clinicopathologic study of 63 cases. Cancer 1982;50:2163-9.

15. Mazur MT, Hsueh S, Gersell DJ. Metastases to the female genital tract. Analysis of 325 cases. Cancer 1984;53:1978-84.

16. Aranda FI, Laforga JB, Martinez MA. Metastasis from breast lobular carcinoma to an endometrial polyp. Acta Obstet Gynecol Scand 1993;72:585-7.

17. Lambot MA, Eddafali B, Simon P, Fayt I, Noel JC. Metastasis from apocrine carcinoma of the breast to an endometrial polyp. Virchows Arch 2001;438:517-8.

18. Sullivan LG, Sullivan JL, Fairey WF. Breast carcinoma metastatic to endometrial polyp. Gynecol Oncol 1990;39:96-8.

19. Silva EG, Jenkins R. Serous carcinoma in endometrial polyps. Mod Pathol 1990;3:120-8.

20. Carcangia ML, Tom LK, Chambers JT. Stage IA uterine serous carcinoma: a study of 13 cases. Am J Surg Pathol 1997; 21:1507-14.
21. Wheeler DT, Bell KA, Kurman RJ, Sherman ME. Minimal uterine serous carcinoma: diagnosis and clinicopathologic correlation. Am J Surg Pathol 2000;24:797-806.

22. McCluggage WG, Sumathi VP, McManus DT. Uterine serous carcinoma and endometrial intraepithelial carcinoma arising in endometrial polyps: report of five cases including two associated with tamoxifen therapy. Hum Pathol (in press).

23. Silva EG, Tornos CS, Follen-Mitchell M. Malignant neoplasms of the uterine corpus in patients treated for breast carcinoma: the effects of tamoxifen. Int J Gynecol Pathol 1994;13:248-58.

24. McCluggage WG, Abdulkader M, Price JH, et al. Uterine carcinosarcomas in patients receiving tamoxifen. A report of 19 cases. Int J Gynecol Cancer 2000;10:280-4.

25. McCluggage WG, McManus DT, Lioe TF, Hill CH. Uterine carcinosarcoma in association with tamoxifen therapy. Br J Obstet Gynaecol 1997;104:748-50.

26. Evans MJ, Langlois NEI, Kitchener HC, Miller ID. Is there an association between long term tamoxifen treatment and the development of carcinosarcoma (malignant mixed Müllerian tumor) of the uterus? Int J Gynecol Cancer 1995:5:310-3.

27. Clement PB, Oliva E, Young RH. Müllerian adenosarcoma of the uterine corpus associated with tamoxifen therapy. A report of six cases and a review of tamoxifen-associated endometrial lesions. Int J Gynecol Pathol 1996;15:222-9.

28. Huang KT, Chen CA, Cheng WF, et al. Sonographic characteristics of adenofibroma of the endometrium following tamoxifen therapy for breast cancer: two case reports. Ultrasound Obstet Gynecol 1996;7:363-6.

29. Pang LC. Endometrial stromal sarcoma with sex cord-like differentiation associated with tamoxifen therapy. South Med J 1998;91:592-4.

30. McCluggage WG, Varma M, Weir P, Bharucha H. Uterine leiomyosarcoma in patient receiving tamoxifen therapy. Acta Obstet Gynecol Scand 1996;75:593-5.

31. Dilts PV, Hopkins MP, Cheng AK, Cody RL. Rapid growth of leiomyoma in patient receiving tamoxifen. Am J Obstet Gynecol 1992;166:167-8.

32. Leo L, Lanza A, Tessarolo RM, Bellino R, Lauricella A, Wierdis T. Leiomyomas in patients receiving tamoxifen. Clin Exp Obstet Gynecol 1994;21:94-8.

\section{ERRATUM}

In the Modern Pathology March 2003 Book Review of Skin Pathology, Second Edition (Mod Pathol 2003;16(3):235), the author's name was misspelled. The correct spelling is Weedon. 